\title{
Measurement of the Cycloidal Drive Sleeves and Pins
}

\author{
Renata ZARĘBA*, Tomasz MAZUR**, Krzysztof OLEJARCZYK***, \\ Damian BZINKOWSKI***** \\ * Kazimierz Pulaski University of Technology and Humanities in Radom, Faculty of Mechanical Engineering, 54 Stasiecki- \\ ego Str., 26-600 Radom, Poland, E-mail: renata.zareba.uth@wp.pl \\ **Kazimierz Pulaski University of Technology and Humanities in Radom, Faculty of Mechanical Engineering, 54 Sta- \\ sieckiego Str., 26-600 Radom, Poland,E-mail: tomasz.mazur@uthrad.pl \\ ***Kazimierz Pulaski University of Technology and Humanities in Radom, Faculty of Mechanical Engineering, 54 Sta- \\ sieckiego Str., 26-600 Radom, Poland, E-mail: k.olejarczyk@uthrad.pl \\ ****Kazimierz Pulaski University of Technology and Humanities in Radom, Faculty of Mechanical Engineering, 54 Sta- \\ sieckiego Str., 26-600 Radom, Poland, E-mail: damianbzinkowski@gmail.com \\ crossref http://dx.doi.org/10.5755/j02.mech.27815
}

\section{Introduction}

Comparison of various drives demonstrated that two stage cycloidal drives are having high efficiency of $92.7 \%$, which was found advantageous [1], thought their efficiency is dependent on the type of bearings [2]. Cycloidal speed reducers perform higher reduction ratio, the higher accuracy, the easier adjustment of the transmission ratio and the smaller workspace than any other [3]. Nevertheless, there are numerous proposals on further improvement of the cycloidal transmissions, such as fabrication of cylindrical tooth profiles [4], tooth modifications $[5,6]$ or non-circular gears [7]. A modification method was proposed to reduce the lost motion [8], and a new concept of two-stage drive with one cycloid disc for each stage was designed [9].

The cycloid disc performance is affected due to the difference between the actual cycloidal speed reducer elements and their theoretical ideal shape and dimensions, so that theoretical position of the components and clearances between them differ from the real contact conditions [10]. There are known kinematic relationships between the fabrication tolerance, drive parameters and performance indices, which are based on the tolerance and enable estimating the magnitude of the backlash of a given drive, as well as estimating the torque ripple [11]. There are also more recent reports on sources and effects of profile design tolerance analysis, including profile reduction, backlash and torque ripple, and maximum gear-ratio [12]. Global sensitivity analysis revealed that the effect on transmission accuracy was larger of the runout error of eccentricity cam, the tooth groove error and accumulative pitch error of cycloid gear, the bearing clearance between cycloid gear and crank shaft, and the tooth groove error and accumulative pitch error of pin gear, large of the runout error of cycloid gear hole at crank shaft and the runout error of carrier hole at crank shaft, small of the assembly error of carrier, the bearing clearance between carrier and frame, etc. [13]. The present study is aimed to the manufacturing accuracy analysis of the sleeves designed for the test purposes in a cycloidal speed reducer.

\section{Cycloidal drive tests and measurement problem}

In the single-stage cycloidal reducers, it is common to apply sliding sleeves in case of very high loads and speeds, especially when reduced noise is required [14]. Fig. 1 presents position of pins $\emptyset 8 \mathrm{f} 71$, small sleeves $\emptyset 12$ s7/Ø8G7 2 and large sleeves $\emptyset 14$ s7/ $\varnothing 10 \mathrm{G} 73$ in the cycloidal drive during the wear tests. There are 16 pins 1,32 small sleeves 2 , i.e. 16 couples, and 8 large sleeves 3 in the assembly.

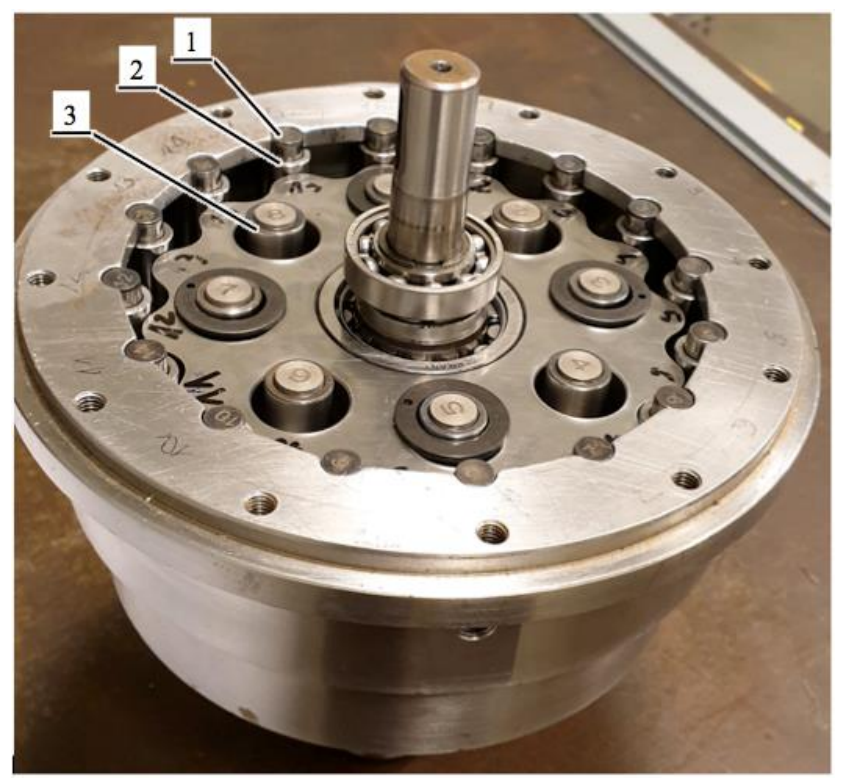

Fig. 1 Picture of the tested cycloidal drive

Correct work of the cycloidal reducer assumes that the load of the input shaft is transmitted to the output one through the cycloidal discs and respective pins and sliding sleeves. Due to the rolling friction, the torque transmitted from the disc to the sleeve causes revolution of the latter, while interaction between the pin and sleeve is rather sliding one. According to the approach described in [2], the actual interaction between the disc and pins covers $50 \%$ of the outer pins. The directions of actual forces during the work are shown in Fig. 2 with the resulting polygon of forces, and graph in Fig. 3 presents an example of the load distribution on the pins. The example concerns with input rotational speed $n=500 \mathrm{rpm}$ and output torque $T=18 \mathrm{Nm}$, reduction ratio was $i=15$. Forces denoted $F_{i}$ and $F_{q i}$ are the loads on the cycloidal disk from internal and external pins, respectively, and $F_{B i}$ corresponds with the forces from the eccentric bearing rollers.

During the tests, the sleeves underwent intensive wear, and sliding friction caused deformations in the material structure. Wear is a phenomenon occurring in multiscale and multiphysics with many intrinsic and extrinsic factors 
of various effect on behavior and wear resistance of materials [15]. Contrary to chemical, atom-by-atom wear, the processes of formation and transportation of wear debris belong to the main physical mechanism of all types of "mesoscopic" wear [16].

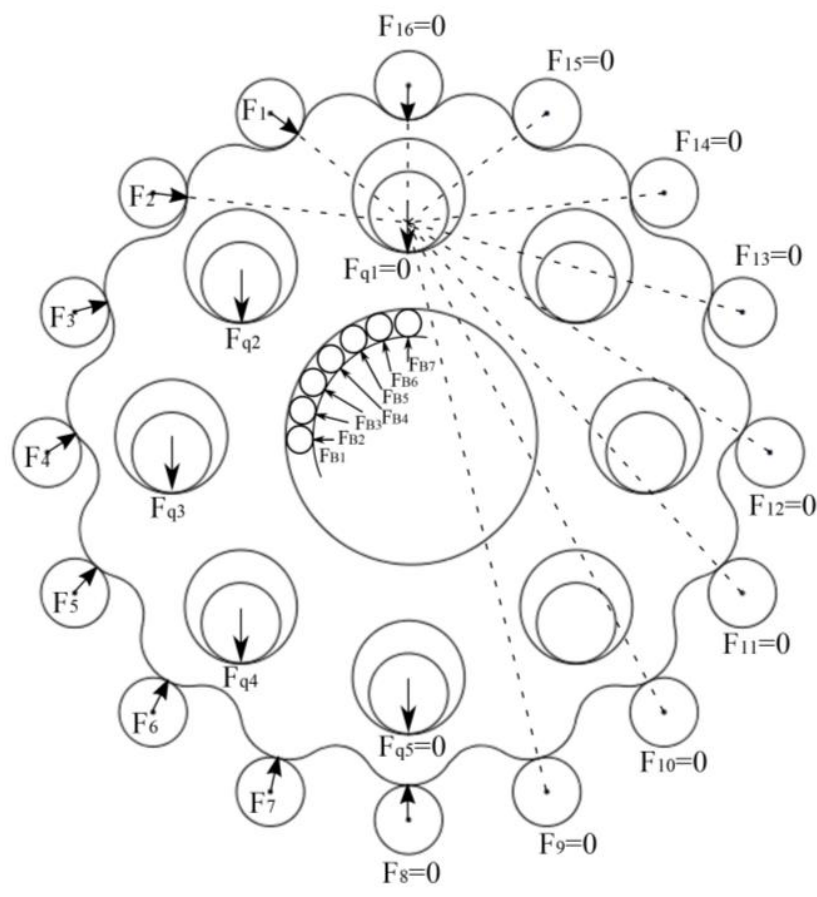

a) Loads on the cycloidal disc

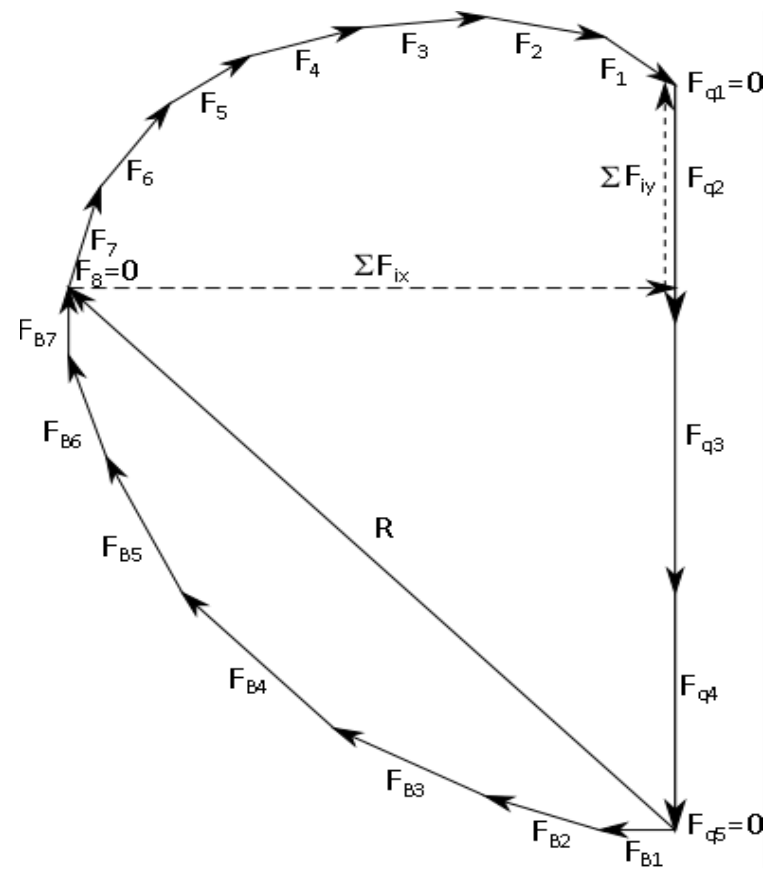

b) The polygon of forces with the resultant force $R$ [2]

Fig. 2 Scheme of cycloidal disc loading [2]

In the tested cycloidal drive, it was found that the sleeves that before tests weighted $5.06 \mathrm{~g}$, lost between 1 and $2 \%$ of their masses due to fatigue wear and damages caused by oil pressure and stretching stresses in the contact area [14]. Both inner and outer diameters became larger after tests. Moreover, dimensional deformations of the sleeves were observed, with asymmetry attributed to the one-sided fixation of the pin to the shaft. However, insufficient accu- racy of the measurement prevented from more detailed analysis of the workload effects on the dimensions and shape of the sleeves.

Thus, it was found necessary to measure geometry of each sleeve before and after load test. In particular, both outer and inner diameters should be measured, along with roundness and cylindricity deviations. For that task, Coordinate Measuring Machine (CMM) was chosen as the most appropriate device.

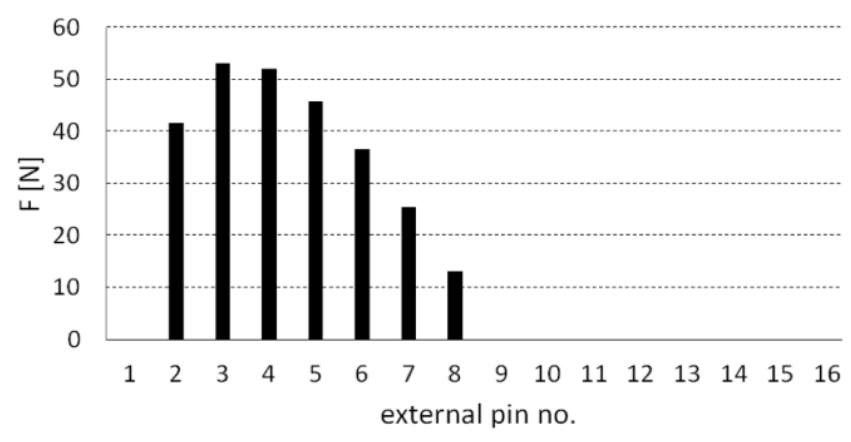

Fig. 3 Example of the forces on the pins [2]

\section{Measurement of sleeves and pins geometry}

CMMs are known for their accuracy and reliability in measurement of geometrical features [17-19]. However, much attention must be paid on the measurement strategy, because the CMM data-fitting algorithms have direct impact on the out-of-roundness measurement [20], as well as the number and distribution of probing points [21] or the stylus tip dimensions [22]. It was demonstrated that CMM measurement of cylindricity provided different results than that of radial method, and differences were attributed to larger uncertainty expressed by maximum permissible error $M P E_{E}$, as well as to smaller number of sampling points [23]. In the case of cycloidal drive sleeves with small inner diameters, CMM measurement was found most appropriate because of quick measurement and similar uncertainty for both outer and inner diameters.

\subsection{Positioning issue during the measurement}

Coordinate measurement results are sensitive to the positioning of the measured pins and sleeves. Fig. 4 shows the fixation of a pin with a V-block in the working space of the coordinate measuring machine.

In the fixation illustrated in Fig. 4, the height of the positioning above the V-block was set with the block gauges. It is one of the basic methods of fixation when a cylindrical part is to be measured with a CMM.

Initial measurement was aimed to definition of local coordinate system for each individual component. In the CMM coordinate system XYZ shown in Fig. 5, outer cylindrical surface was used to collect 4 probing points (denoted $1,2,3$, and 4) in each of three cross-sections parallel to the $\mathrm{XY}$ plane. The probe tip movement along $\mathrm{X}$ and $\mathrm{Y}$ axes determined the reference plane XY.

From the as-obtained 12 points, the cylinder was calculated with its axis considered the z-axis of the local coordinate system xyz for this particular cylindrical part. However, this procedure generates certain errors due to the actual direction of the probe tip movement, which should correspond with the radius vector of the cylinder in the contact 
point. This error has no significant effect on the results of measurement, if the declination angles are small enough. On the other hand, it can be only by accident, when the axes $\mathrm{Z}$ and $\mathrm{Z}$ are coaxial. The Table 1 shows examples of the declination angles of $\mathrm{z}$-axis for 16 measured pins.

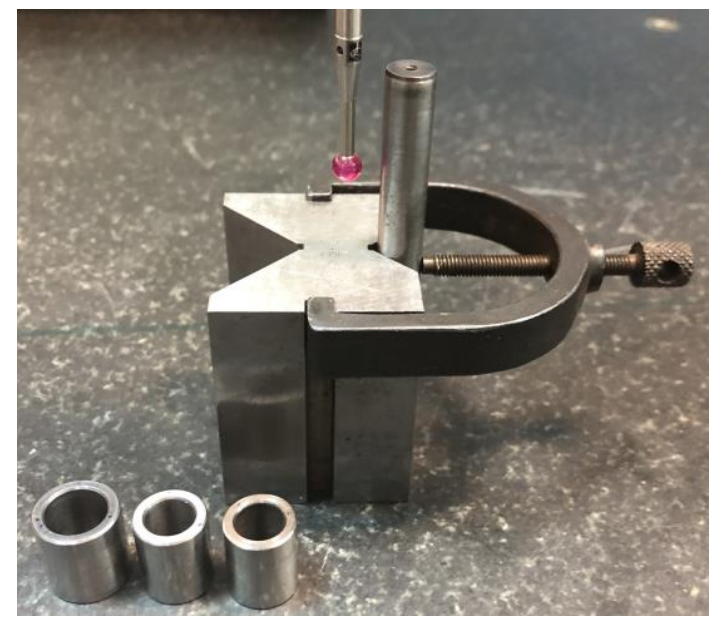

Fig. 4 Fixation of a pin during the CMM measurement

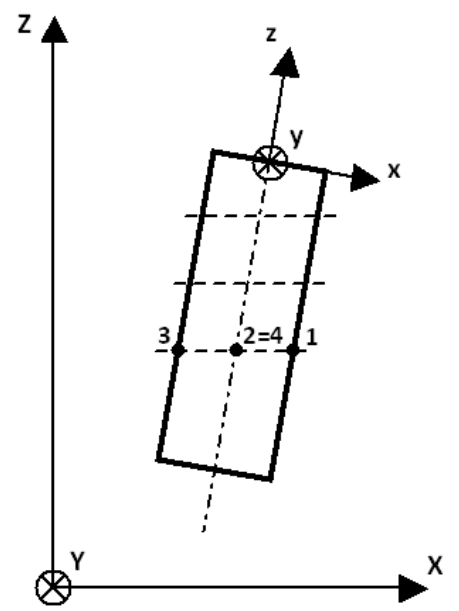

Fig. 5 Initial measurement for setting local coordinate axis $\mathrm{z}$ (here $\mathrm{Y}$ and $\mathrm{y}$ axes have the same direction)

Table 1

Declination of the local z-axis in the XYZ system

\begin{tabular}{|c|c|c|c|}
\hline Pin No. & $\begin{array}{c}\text { Declination } \\
\text { to } \mathrm{X} \text { axis }\end{array}$ & $\begin{array}{c}\text { Declination } \\
\text { to } \mathrm{Y} \text { axis }\end{array}$ & $\begin{array}{c}\text { Declination } \\
\text { to } \mathrm{Z} \text { axis }\end{array}$ \\
\hline 1 & 90-16’04" & 90-00’49" & 179-43'55" \\
\hline 2 & 90-32'29" & 90-32'10" & 179-14'17" \\
\hline 3 & 90-44’01" & 89-42'59" & 179-12’49" \\
\hline 4 & 90-32’42" & 90-06’39" & 179-26’38" \\
\hline 5 & 91-14'51" & 89-24’04" & 178-36'58" \\
\hline 6 & 90-33'27" & 90-14’20" & 179-23'36" \\
\hline 7 & 91-02’35" & 90-01'53" & 178-57'24" \\
\hline 8 & 90-39'18" & 89-46’09" & 179-18'20" \\
\hline 9 & 90-59’01" & 90-12'58" & 178-59'35" \\
\hline 10 & 91-35'22" & 89-37'10" & 178-21'57" \\
\hline 11 & 90-40’32" & 90-11'04" & 179-17'59" \\
\hline 12 & 91-47’28" & 89-40’03" & 178-10’42" \\
\hline 13 & 90-44'45" & 90-40’37" & 178-59'33" \\
\hline 14 & 90-56’03" & 89-43'56" & 179-01'42" \\
\hline 15 & 90-57’44" & 89-46’28" & 179-00`42" \\
\hline 16 & 90-17'54" & 90-24’48" & 179-29'25" \\
\hline
\end{tabular}

In the next stages of determination of the local coordinate system, 4 symmetrically distributed points were collected on the upper plane of the cylindrical part. From these points, the basic plane xy was calculated with the coordinate system center in the point of its intersection with the axis of the abovementioned calculated cylinder.

\subsection{Measurement strategy}

The measurements of sleeves were conducted using CMM made by Mitutoyo, type CRYSTA-APEX C 7106 with measurement range (X/Y/Z): 705/1005/605 [mm] and resolution $0.1 \mu \mathrm{m}$. Measuring head was made by Renishaw, type SP25M, and standard software was MCOSMOS. This machine was designed for demanding measurement tasks both in laboratory and in industrial conditions. It has integrated temperature errors compensation and vibration recognition system. The CMM can be driven manually through a joystick or digitally in $\mathrm{CNC}$ mode. Measurement speed in CNC mode is from 1 to $8 \mathrm{~mm} / \mathrm{s}$, and up to $3 \mathrm{~mm} / \mathrm{s}$ in the manual mode. High measuring speed is very important for small details measurement and contributes to short measurement time.

The maximum permissible error of CRYSTAAPEX C 7106 CMM, as defined in standards PN-EN ISO 10360-2:2003 and ISO 10360-4:2002, was $M P E_{E}=(1.7+$ $+4 \cdot \mathrm{L} / 1000) \mu \mathrm{m}$, and that of measuring head $M P E_{P}=1.7 \mu \mathrm{m}$, for the scanning mode $M P E_{T H P}=2.3 \mu \mathrm{m}$. The expanded uncertainty for level of confidence $p=0.95$ and coverage factor $k=2$, according to the document EA4/02 was determined as follows:

$U_{E}=(0.4+1 \cdot 10-6 \cdot \mathrm{L}) \mu \mathrm{m}$ for the length measurement; $U_{P}=0.3 \mu \mathrm{m}$ for the probing head and $U_{T H P}=0.6 \mu \mathrm{m}$ for the scanning mode.

In case of such a small detail, the scanning mode would not provide substantial savings of measurement time. Moreover, it generated larger permissible error and provided wider uncertainty range, so it was not used in the researches.

Initial scanning was made in order to determine expected out-of-roundness type, so that proper measuring strategy could be chosen. Fig. 6 presents the results for both outer (1a) and inner (1b) diameters of the sleeve \#30-1. Both diameters revealed distinguishable ovality.

The dimensions of sleeves and probing points distribution are shown in Fig. 7, a. There were two types of sleeves, \#1 and \#2, their outer diameters a and inner diameters b were as follows: outer diameters with tolerances $a_{1}=$ $\varnothing 12 \mathrm{~s} 7(+0.046 /+0.028)$ and $a_{2}=\varnothing 14 \mathrm{~s} 7(+0.046 /+0.028)$; inner diameters with tolerances $b_{1}=\varnothing 8 \mathrm{G} 7(+0.020 /+0.005)$ and $b_{2}=\varnothing 10 \mathrm{G} 7(+0.020 /+0.005)$; length of each sleeve was $h=15$ js 13 .

Based on the expected ovality of the diameters, the measurement strategy was chosen as follows. Diameters and roundness were measured with 8 probing points each, in two parallel intersections, $I$ and $I I$, as shown in Fig. 7, a.

CMM measurement strategy requires definition of the coordinate system. As it is seen in Fig. 7, the coordinate axes were defined in the measured sleeve's system, so that $z$-axis was placed along the cylinder's axis, and the zero point was put in its upper plane. All the probing points were collected with the same probing head, the contact direction was radial. Function "circle measurement" was applied, 
where outer diameters were assumed as minimum circumscribed circles (MCCI), while inner diameters as maximum inscribed circles (MICI).

In order to detect possible out-of-roundness, each diameter was calculated three times: 1) one from points 1 , 3,5 , and $7 ; 2$ ) one from points $2,4,6$, and $8 ; 3$ ) and one from all eight points.

In addition, calculation error was determined for each result, generated from the assumed algorithm MCC/MIC and actual roundness deviation. To assess the applicability of this strategy to the measurement task, 50 repetitions were made for one sleeve in the same repeatability conditions.

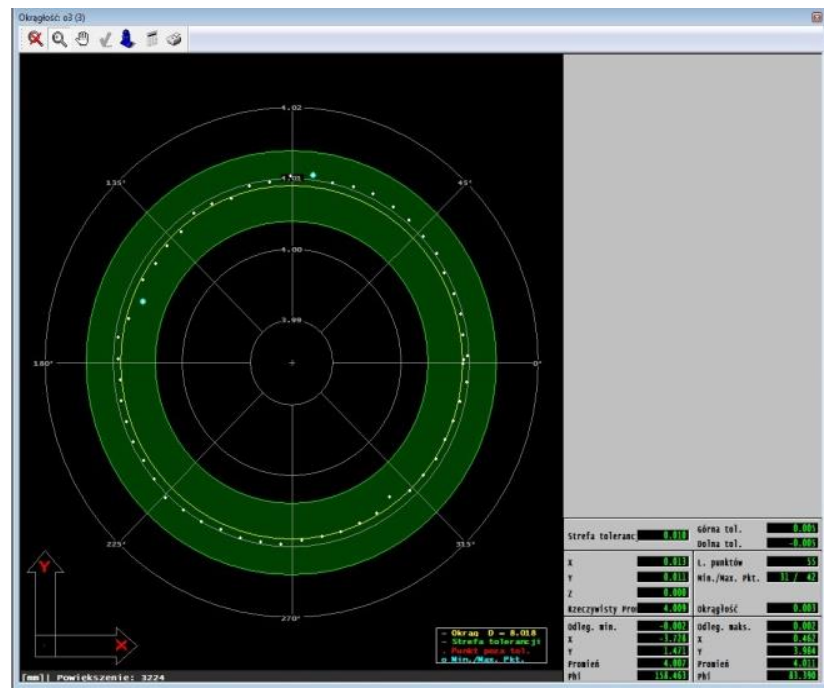

a) Outer diameter

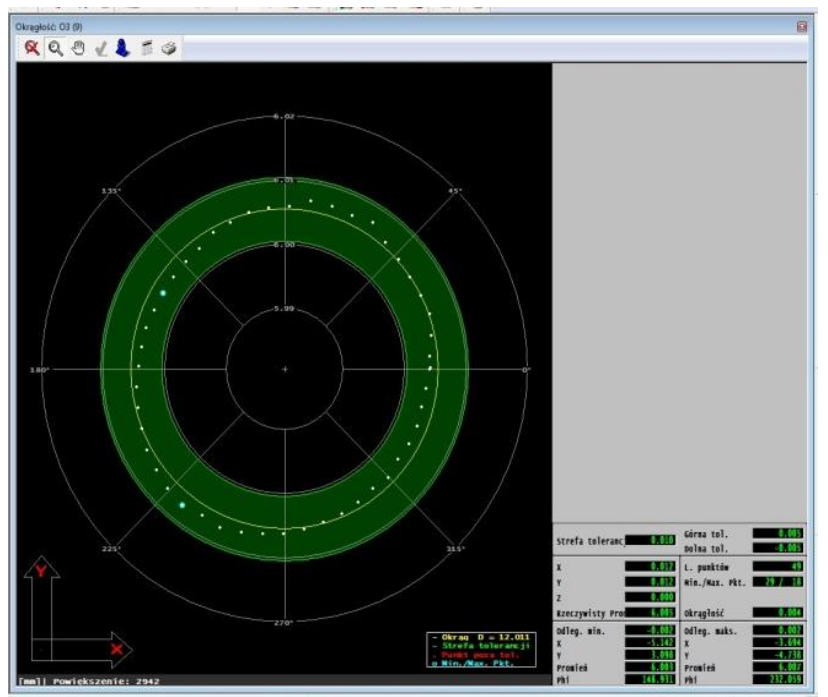

b) Inner diameter

Fig. 6 Screenshots of the initial scanning results for the sleeve \#30-1

Measured pins required different measurement strategy because of small dimensions and difficult fixation. Higher ratio of length to diameter and cylindricity tolerance forced to increase the number of measured intersections up to 7, marked from $I$ to VII in Fig. 7, b. Pin had length $l=$ $=40 \pm 0.2 \mathrm{~mm}$, its diameter with tolerance was $\varnothing 8 \mathrm{f} 7$ (-0.013/ -0.028), and the coordinate system was determined in similar way as for the sleeves. However, fixation of the pins in CMM measuring space required two configuration of the probing head, \#P1 and \#P2, of different declination angle.
Then, with the configuration \#P1, points 1, 2, 3, 4, and 5 (total 30 points) were measured in each intersection, while with the configuration \#P2, points 6,7 , and 8 (total 18 points) were measured. This way, eight points were collected in each intersection, steadily distributed on the circle. Such a strategy had two important merits: the pin was measured along its entire length with only small area of fixation ca. $5 \mathrm{~mm}$ left out; all probing points for cylindricity deviation assessment were collected in one fixation.

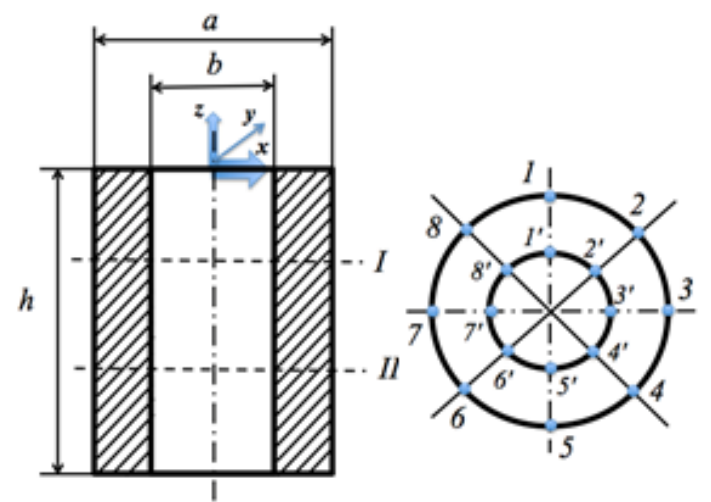

a) Illustration of measurement points location on the sleeve

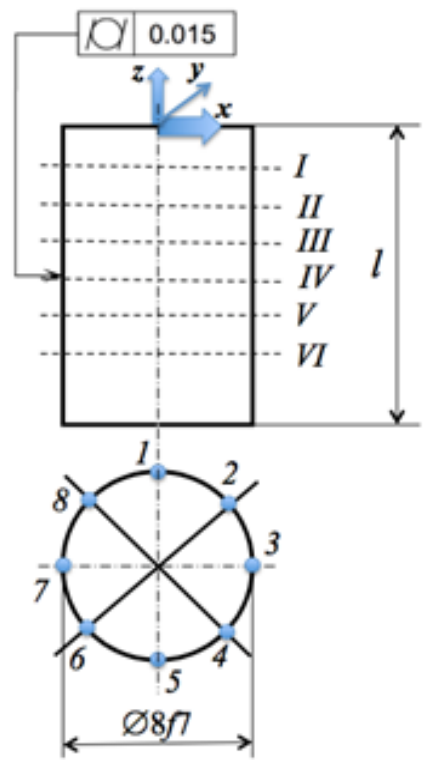

b) Illustration of measurement points location on the pins

Fig. 7 Dimensions, probing point locations and coordinate systems of the CMM measurement of the sleeves and pins

Similarly, as for sleeves, each pin diameter was calculated three times: 1 ) one from points $1,3,5$, and $7 ; 2$ ) one from points $2,4,6$, and $8 ; 3$ ) and one from all eight points.

In addition, calculation error was determined for each result, generated from the assumed algorithm $\mathrm{MCC} / \mathrm{MIC}$ and actual roundness deviation. Cylindricity was calculated from 48 points, 6 circles 8 points each, using minimum circumscribed cylinder (MCCY) and least-square axis (LSCY) [24], since some differences may be expected because of different best-fit methods $[25,26]$.

\subsection{Measurement results and discussion}

Measurement of the pin diameters repeated 50 times revealed interesting characteristics. Fig. 8, a presents 
the example results of measurements and calculations of the pin \#14 diameter, and Fig. 8, b presents obtained out-ofroundness values. In Fig. 8, a, there are also shown values of $M P E_{E}=1.7 \mu \mathrm{m}$, since the impact of measured length $L$ was negligible.

It should be noted that diameters calculated from 4 points always tended to be smaller than that from 8 points, and the difference reached up to $6 \mu \mathrm{m}$ in intersection $V I$, which was more than 3 times larger than $M P E_{E}=1.7 \mu \mathrm{m}$. In the same intersection, the largest out-of-roundness was found, almost $12 \mu \mathrm{m}$, which can be attributed to the machining inaccuracy and deformations of the pin in this intersection. Difference of out-of-roundness values obtained from points $1,3,5,7$ and the one from points $2,4,6,8$ was almost $2 \mu \mathrm{m}$.

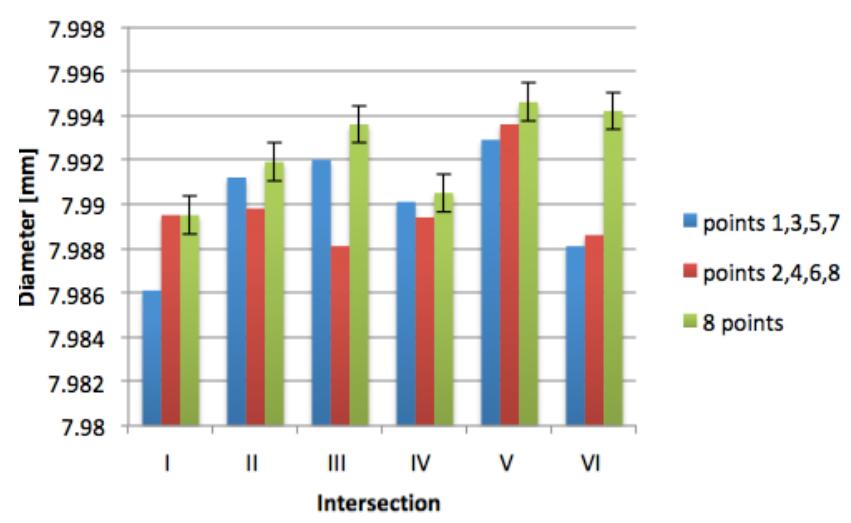

a) Mean values for different calculations of diameter

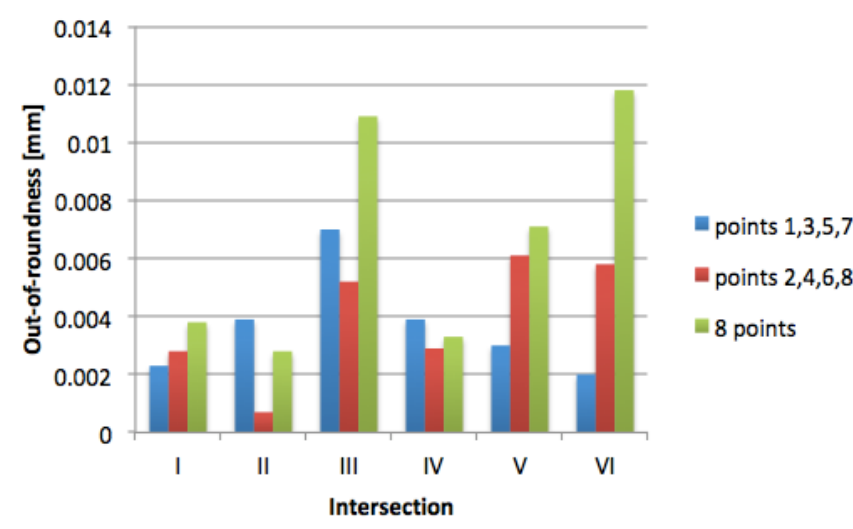

b) Mean values for different calculations of out-of-roundness

Fig. 8 Results of repetitions of the pin measurements

In the analysis, it is important to consider the errors generated by the fitting method [27]. Cylindricity deviation defined as the greatest difference between the actual surface from the CAD model [28] was calculated for MCCY and LSCY fitting methods. Diameters determined from these methods were 7.9991 and $7.9889 \mathrm{~mm}$, respectively. Average difference between obtained MCCY and LSCY diameters from 50 repetitions was $10 \mu \mathrm{m}$. Respective cylindricity deviations were 0.0179 and $0.0185 \mathrm{~mm}$, both of them above the assumed tolerance of $0.015 \mathrm{~mm}$. It is noteworthy that from the application perspective, MCCY method reflects better the presence of material and its further removal during the tests.
Having 50 repetitions of each intersection measurement, it was possible to estimate part variation $P V$ from the formula as follows [29]:

$$
P V=R_{p} \cdot K_{3}
$$

where: $R_{p}$ is a range of the obtained mean values $x_{p i}$ and $K_{3}$ is a factor dependent on confidence level and on the number of measured details. In our case, the measurement was performed in 6 intersections, so it was assumed for confidence level of $99 \%, K_{3}=2.93$ [28]. From the diagram in Fig. 8a it is seen that $x_{p \min }=7.9895 \mathrm{~mm}$ corresponds with the diameter in intersection $I$, while $\bar{x}_{\text {pmax }}=7.9946 \mathrm{~mm}$ belongs to intersection $V$, giving $R_{p}=0.0051 \mathrm{~mm}$. Thus, the part variation was calculated as follows:

$$
P V=0.0051 \cdot 2.93 \approx 0.0149 \mathrm{~mm}
$$

It is striking that the part variation is almost equal to the assumed cylindricity tolerance, so that the difference is smaller than the measurement uncertainty. Thus, when the tolerance is taken as a reference value $R F=0.015 \mathrm{~mm}$, it provides percent part variation as follows:

$$
\% P V=\frac{P V}{R F} \cdot 100 \%=99,3 \%
$$

The equation (3) demonstrates that almost entire tolerance bandwidth is consumed by $P V$. As a result, it can be expected that this particular pin will perform unsteady wear because of inevitably unsteady load distribution. Its surface integrity cannot be kept in the intersections III, V and $V I$, where diameters are the largest and out-of-roundness the highest. In the case of sleeves, there are two diameters tolerated. The Tables 2 and 3 show two examples of the results, where one diameter is suitable while the other can be accepted with caution, based on the cylindricity measurement from 16 points, as described above in the section 3.2 .

In particular, the sleeve \#23 from the first group with dimensions $a_{1}=\varnothing 12 \mathrm{~s} 7$ and $b_{1}=\varnothing 8 \mathrm{G} 7$ fully suited to the inner diameter tolerance, as it is seen in the Table 2. However, its outer diameter was too small in the intersection $I I$, emphasized with bold font, $4 \mu \mathrm{m}$ below the acceptable tolerance. Even though the sleeve \#23-1 can be accepted for the wear experiments on the test rig, it should be kept in mind, that its diameter in the intersection $I I$ was initially smaller than the minimal acceptable size.

Similarly, the sleeve \#2-2 from the second group with dimensions $a_{2}=\varnothing 14 \mathrm{~s} 7$ and $b_{2}=\varnothing 10 \mathrm{G} 7$ fully suited to the outer diameter tolerance. The Table 3 shows that its inner diameter was found to exceed the acceptable size 10.020 $\mathrm{mm}$ in intersection $I$. Provided inscribed cylinder MICY had diameter $10.017 \mathrm{~mm}$, the sleeve can be accepted for the experiments. However, its wear after tests can be expected more unsteady because of large difference $10 \mu \mathrm{m}$ between diameters in two intersections and of large deviation from cylindricity $\delta_{b 2}=12 \mu \mathrm{m}$.

Interesting cases revealed the sleeves from the first group \#27-1 and \#29-1. Each of them exceeded the tolerance only in one 4-points diameter, but with different effects on the overall result, as it is shown in Table 4. In the sleeve 
\#27-1, intersection $I$ diameter calculated from the points 1 , 3,5 , and 7 appeared to be smaller than all other, below the acceptable size $12.028 \mathrm{~mm}$. It did not affect much the overall result $12.031 \mathrm{~mm}$ for the cylinder MCCY calculated from 16 points with deviation $5 \mu \mathrm{m}$. However, if left unnoticed, this result would introduce some interpretational errors after wear tests.
Namely, two different diameters obtained in the same intersection after rotation $45^{\circ}$, indicate potentially unsteady load on the surface during the tests, and consequently intensified wear. On the other hand, smaller diameter means that there is smaller amount of material to be removed. As a result, wear analysis can be misinterpreted and exaggerated.

Table 2

Results of the measurement for the sleeve \#23-1

\begin{tabular}{|c|c|c|c|c|}
\hline Measurement strategy (described in Fig. 7) & Diameter $b_{1}, \mathrm{~mm}$ & Deviation $\delta_{b 1}, \mathrm{~mm}$ & Diameter $a_{1}, \mathrm{~mm}$ & Deviation $\delta_{a 1}, \mathrm{~mm}$ \\
\hline Intersection $I$ from points 1, 3, 5, 7 & 8.017 & 0.008 & 12.029 & 0.004 \\
\hline Intersection I from points 2, 4, 6, 8 & 8.019 & 0.003 & 12.029 & 0.004 \\
\hline Intersection $I I$ from points 1, 3, 5, 7 & 8.014 & 0.01 & $\mathbf{1 2 . 0 2 4}$ & 0.004 \\
\hline Intersection II from points 2, 4, 6, 8 & 8.014 & 0.01 & $\mathbf{1 2 . 0 2 4}$ & 0.005 \\
\hline Intersection $I$ from 8 points & 8.017 & 0.007 & 12.029 & 0.004 \\
\hline Intersection II from 8 points & 8.014 & 0.008 & $\mathbf{1 2 . 0 2 4}$ & 0.005 \\
\hline Cylinder from 16 points & 8.014 & 0.011 & 12.029 & 0.006 \\
\hline
\end{tabular}

Table 3

Results of the measurement for the sleeve \#2-2

\begin{tabular}{|c|c|c|c|c|}
\hline Measurement strategy (described in Fig. 7) & Diameter $b_{2}, \mathrm{~mm}$ & Deviation $\delta_{b 2}, \mathrm{~mm}$ & Diameter $a_{2}, \mathrm{~mm}$ & Deviation $\delta_{a 2}, \mathrm{~mm}$ \\
\hline Intersection $I$ from points $1,3,5,7$ & $\mathbf{1 0 . 0 2 7}$ & 0.001 & 14.04 & 0.001 \\
\hline Intersection $I$ from points $2,4,6,8$ & $\mathbf{1 0 . 0 2 7}$ & 0.002 & 14.042 & 0.005 \\
\hline Intersection $I I$ from points $1,3,5,7$ & 10.017 & 0.001 & 14.037 & 0.004 \\
\hline Intersection $I I$ from points $2,4,6,8$ & 10.017 & 0.004 & 14.038 & 0.006 \\
\hline Intersection $I$ from 8 points & $\mathbf{1 0 . 0 2 7}$ & 0.002 & 14.042 & 0.005 \\
\hline Intersection $I I$ from 8 points & 10.017 & 0.003 & 14.038 & 0.005 \\
\hline Cylinder from 16 points & 10.017 & 0.012 & 14.042 & 0.008 \\
\hline
\end{tabular}

Table 4

Results of the measurement for the sleeves \#27-1 and \#29-1

\begin{tabular}{|c|c|c|c|c|}
\hline \multirow{2}{*}{ Measurement strategy (described in Fig. 7) } & \multicolumn{2}{|c|}{$\# 27-1$} & \multicolumn{2}{|c|}{$\# 29-1$} \\
\cline { 2 - 5 } & Diameter $a_{1}, \mathrm{~mm}$ & Deviation $\delta_{a 1, \mathrm{~mm}}$ & Diameter $a_{1}, \mathrm{~mm}$ & Deviation $\delta_{a 1}, \mathrm{~mm}$ \\
\hline Intersection $I$ from points 1, 3, 5, 7 & 12.027 & 0 & 12.04 & 0.005 \\
\hline Intersection $I$ from points 2, 4, 6, 8 & 12.03 & 0.008 & 12.038 & 0.005 \\
\hline Intersection $I I$ from points $1,3,5,7$ & 12.028 & 0.002 & $\mathbf{1 2 . 0 4 9}$ & 0.008 \\
\hline Intersection $I I$ from points 2, 4, 6, 8 & 12.031 & 0.006 & 12.045 & 0.005 \\
\hline Intersection $I$ from 8 points & 12.03 & 0.006 & 12.04 & 0.005 \\
\hline Intersection $I I$ from 8 points & 12.031 & 0.005 & $\mathbf{1 2 . 0 4 9}$ & 0.008 \\
\hline Cylinder from 16 points & 12.031 & 0.005 & $\mathbf{1 2 . 0 4 9}$ & 0.015 \\
\hline
\end{tabular}

Different effect had the result calculated from the points 1, 3, 5, and 7 in intersection $I I$ of the sleeve \#29-1. It was $12.049 \mathrm{~mm}, 3 \mu \mathrm{m}$ above the maximal acceptable size, and its out-of-roundness was $8 \mu \mathrm{m}$. However, MCCY diameter from 16 points was $12.049 \mathrm{~mm}$, too, which formally may result with rejection of this sleeve. From the technical point of view, rejection is unnecessary, because after initial wear of the small amount of material during the test, the load will become more steady and wear will be slowed down.

\section{Conclusions}

The analysis of measurement results demonstrated that the measurement strategy was chosen correctly. It was confirmed that the obtained MCCY and MCCI diameters were generally larger hen LSCY and LSCI ones, so that respective MCCY/MICY or MCCI/MICI fitting methods must reflect the amount of material. Measurement in different intersections and at different rotation angles provided additional information that will be helpful in the analysis of wear of cycloidal drive sleeves and pins. In particular, not only dimensional tolerances were calculated, but also local deviations from the assumed diameter and shape were revealed.

As a result, it was demonstrated that:

- presumably most accurate calculations from more probing points did not reveal features important for further wear analysis;

- some of the sleeves and pins with MCCY/MICY or MCCI/MICI diameters outside acceptable size might not be rejected, based on the particular results obtained from 4 points;

- additional attention must be paid on the wear of the sleeves and pins with MCCY/MICY diameters within the tolerances, where particular 4-points results indicated large difference.

Part variation $\% P V=99.3 \%$ indicated that almost entire tolerance bandwidth is consumed by the dimensional variations of the part. From the wear test perspective, it is unfavorable index because of unsteady load distribution and subsequent unsteady wear. Thus, it is highly recommended to introduce some correction to the machining procedure of the cycloidal drive sleeves and pins destined to the wear test. 


\section{Acknowledgement}

The test rig was designed and built up in cooperation between UTH Radom and Airbus Helicopters, project No. IPAH7409N.

\section{References}

1. Tejaswini, G.; Reddy, C. M. 2015. Compatibility of various high ratio gear technologies to fit in a small volume - a review, International Journal \& Magazine of Engineering, Technology, Management and Research 2(7):56-60.

2. Olejarczyk, K.; Wikło, M.; Kołodziejczyk, K. 2019. The cycloidal gearbox efficiency for different types of bearings - sleeves vs. needle bearings, Proceedings of the Institution of Mechanical Engineers, Part C: Journal of Mechanical Engineering Science 233(21-22):74017411. https://doi.org/10.1177/0954406219859903.

3. Shin, J. H.; Kwon, S. M. 2006. On the lobe profile design in a cycloid reducer using instant velocity center, Mechanism and Machine Theory 41: 596-616. https://doi.org/10.1016/j.mechmachtheory.2005.08.001.

4. Yan, H. S.; Lai, T. S. 2002. Geometry design of an elementary planetary gear train with cylindrical tooth- profiles, Mechanism and Machine Theory 37: 757-767. https://doi.org/10.1016/S0094-114X(02)00009-5.

5. Lin, W. S.; Shih, Y. P; Lee, J. J. 2014. Design of a twostage cycloidal gear reducer with tooth modifications, Mechanism and Machine Theory 79: 184-197. https://doi.org/10.1016/j.mechmachtheory.2014.04.009.

6. Ren, Z. Y.; Mao, S. M.; Guo, W. C; Guo, Z. 2017. Tooth modification and dynamic performance of the cycloidal drive, Mechanical Systems and Signal Processing 85: 857-866. https://doi.org/10.1016/j.ymssp.2016.09.029.

7. Mundo, D. 2006. Geometric design of a planetary gear train with non-circular gears, Mechanism and Machine Theory 41: 456-472. https://doi.org/10.1016/j.mechmachtheory.2005.06.003.

8. Sun X.; Han L.; Ma K; Li L.; Wang J. 2018. Lost motion analysis of CBR reducer, Mechanism and Machine Theory 120: 89-106. https://doi.org/10.1016/j.mechmachtheory.2017.09.019.

9. Blagojevic, M.; Marjanovic, N.; Djordjevic, Z.; Stojanovic, B.; Disic, A. 2011. A new design of a twostage cycloidal speed reducer, J. Mech. Des. 133(8): 085001-1.

https://doi.org/10.1115/1.4004540.

10. Kostić, N.; Blagojević, M.; Petrović, N.; Matejić, M.; Marjanović, N. 2018. Determination of real clearances between cycloidal speed reducer elements by the application of heuristic optimization, Transactions of FAMENA 42(1):1 5-26. https://doi.org/10.21278/TOF.42102.

11. Yang, D. C. H.; Blanche, J. G. 1990. Design and application guidelines for cycloid drives with machining tolerances, Mechanism and Machine Theory 25(5): 487501. https://doi.org/10.1016/0094-114X(90)90064-Q.

12. Sensinger, J. W. 2010. Unified approach to cycloid drive profile, stress, and efficiency optimization, J. Mech. Des. 132(2): 024503. https://doi.org/10.1115/1.4000832.
13. Han, L.; Guo, F. 2016. Global sensitivity analysis of transmission accuracy for RV-type cycloid-pin drive, J. Mech. Sci. Technol. 30: 1225-1231.

https://doi.org/10.1007/s12206-016-0226-2.

14. Żurowski, W.; Olejarczyk, K.; Zaręba, R. 2019. Wear assessment of sliding sleeves in a single-stage cycloidal drive, Advances in Science and Technology Research Journal 13(4): 239-245. https://doi.org/10.12913/22998624/114180.

15. Cao, H.; Tian, Y.; Meng, Y. 2021. A fracture-induced adhesive wear criterion and its application to the simulation of wear process of the point contacts under mixed lubrication condition, Facta Universitatis Series: Mechanical Engineering 19(1): 23-38. https://doi.org/10.22190/FUME210108021C.

16. Popov, V. 2019. Generalized Archard law of wear based on Rabinowicz criterion of wear particle formation, Facta Universitatis Series: Mechanical Engineering 17(1): 39-45. https://doi.org/10.22190/FUME190112007P.

17. Kubátová, D.; Melichar, M.; Kutlwašer, J. 2017. Evaluation of repeatability and reproducibility of CMM equipment, Procedia Manufacturing 13: 558-564. https://doi.org/10.1016/j.promfg.2017.09.091.

18. Lorenzo, L.; Peláez, G.; Ares, E. 2017. Quality assurance program for CMM in production, Procedia Manufacturing 13: 616-622. https://doi.org/10.1016/j.promfg.2017.09.125.

19. Gapinski, B.; Wieczorowski, M.; Marciniak-Podsadna, L.; Dybala, B.; Ziolkowski, G. 2014. Comparison of different method of measurement geometry using CMM, Optical Scanner and Computed Tomography 3D, Procedia Engineering 69: 255-262. https://doi.org/10.1016/j.proeng.2014.02.230.

20. Liu, Q.; Zhang, C. C.; Wang, H. P. B. 2001. On the effects of CMM measurement error on form tolerance estimation, Measurement 30(1): 33-47. https://doi.org/10.1016/S0263-2241(00)00056-7.

21. Gapinski, B.; Rucki, M. 2008. The roundness deviation measurement with CMM, Proc. IEEE AMUEM-2008, Sardagna - Trento, Italy, 108-111. https://doi.org/10.1109/AMUEM.2008.4589944.

22. Zelinka, J.; Čepová, L.; Gapiński, B.; Čep, R.; Mizera, O.; Hrubý, R. 2019. The effect of a stylus tip on roundness deviation with different roughness, M. Diering et al. (eds) Advances in Manufacturing II - Volume 5, LNME, Springer, Cham, pp. 147-157. https://doi.org/10.1007/978-3-030-18682-1_12

23. Adamczak, S.; Janecki, D.; Makieła, W.; Stępień, K. 2010. Quantitative comparison of cylindricity profiles measured with different methods using Legendre-Fourier coefficients, Metrol. Meas. Syst. 17(3): 397-404. https://doi.org/10.2478/v10178-010-033-5.

24. Whitehouse, D. J. 2010. Handbook of Surface and Nanometrology. CRC Press, Boca Raton.

25. Toteva, P.; Vasileva, D. 2018. Associated elements for assessment the deviation of cylindrical surfaces form, Procedia Manufacturing 22: 49-56. https://doi.org/10.1016/j.promfg.2018.03.009.

26. Dovica, M.; Vegh, A. 2013. Comparison of the cylindricity deviation using different evaluation methods, American Journal of Mechanical Engineering 1(7): 339342.

https://doi.org/10.12691/ajme-1-7-37. 
27.Swornowski, P.; Rucki, M. 2003. The erors pccurring in the CMM fitting method, Measurement Science Review 3(3): 135-138.

28. Poniatowska, M. 2012. Deviation model based method of planning accuracy inspection of free-form surfaces using CMMs, Measurement 45(5): 927-937. https://doi.org/10.1016/j.measurement.2012.01.051.

29. Dietrich, E.; Schultze, A. 2011. Measurement Process Qualification: Gauge Acceptance and Measurement Uncertainty According to Current Standards. Hanser, München.
R. Zaręba, T. Mazur, K. Olejarczyk, D. Bzinkowski

\section{MEASUREMENT OF THE CYCLOIDAL DRIVE SLEEVES AND PINS}

\section{S u m m a r y}

In the paper, an issue of CMM measurement strategy of the sleeves and pins designed for wear tests in the cycloidal drive. The measurement strategy was proposed, based on initial out-of-roundness measurement in scanning mode. Proposed approach ensured that the pin was measured along its entire $40 \mathrm{~mm}$ length with only small area of fixation ca. $5 \mathrm{~mm}$ left out, and all probing points for cylindricity deviation assessment were collected in one fixation. It was demonstrated that the cylindricity and roundness measurement results based on 8,16 and 48 probing points provided sufficient data for further wear analysis. In some cases, the circles calculated from 4 points gave additional insights allowing to accept the part that otherwise might be possibly rejected.

Keywords: cycloidal drive, tolerances, wear test, measurement strategy, CMM.

Received October 07, 2020

Accepted December 07, 2021

This article is an Open Access article distributed under the terms and conditions of the Creative Commons Attribution 4.0 (CC BY 4.0) License (http://creativecommons.org/licenses/by/4.0/). 